\title{
Otimização do Corte de Polipropileno com Jato Abrasivo
}

\author{
Wildor T. Hennies, Carlos T. Lauand, Guillermo R. Martín Cortés \\ Departamento de Engenharia de Minas e de Petróleo, Escola Politécnica, USP \\ Francisco R. Valenzuela Diaz \\ Departamento de Engenharia de Metalurgia e Materiais, Escola Politécnica, USP
}

\begin{abstract}
Resumo: A tecnologia avançada de corte com jato de água pode ser usada em chapas de polipropileno. Os modernos sistemas são compostos por: bomba de alta pressão, mesa XY e computador. O corte no sistema cria uma ranhura com características próprias. A largura do sulco é maior na entrada que na saída do corte. No corte do polipropileno podem surgir rebarbas na base da chapa como pequenas fibras. Experiência adquirida na confecção de peneiras mostrou que o número de furos é decisivo no custo da peça. Ensaios preliminares simularam alternativas de corte com e sem abrasivo. A abertura de 900 furos numa área de $967 \mathrm{~cm}^{2}$ revelou consumir 126 minutos para corte sem abrasivo, contra 201 no caso mais oneroso. A seguir, novos desenhos foram propostos diminuindo a malha, mas, preservando o índice de vazamento. Assim, 145, 218 ou 362 furos são possíveis. O corte de velocidade constante e com abrasivo mostrou-se o mais eficiente. Por outro lado, o modo de abrir o furo influi na qualidade da peneira. A seleção da alternativa adequada, os problemas surgidos durante a investigação e as soluções adotadas foram detalhadamente descritos no estudo.
\end{abstract}

Palavras-chave: Corte com jato d'água, jatos d'água puros e com abrasivo, corte de chapas de polipropileno, otimização de corte.

\section{Optimization of Polypropylene Waterjet Cut}

Abstract: Advanced technology of waterjet cut can be used in polypropylene tableware. The modern systems comprise a high-pressure pump, $\mathrm{XY}$ table and computer as controller. The cutting process may lead to kerfs with specific characteristics. The kerf width is larger in the entrance than in the jet exit. In cutting polypropylene, burrs in the base of the plate can appear as small staple fibers. Experience acquired in the confection of sieves showed that the number of punctures is decisive in the cost of the part. Preliminary assays simulated cut alternatives with and without abrasive. The opening of 900 punctures in an area of $967 \mathrm{~cm}^{2}$ consumes 126 minutes for cutting without abrasive, in contrast to 201 minutes in the most costly case. New drawings were then considered with the meshes being decreased, but preserving the emptying index. Thus, 145, 218 or 362 punctures are possible. The cutting at a constant speed and using abrasive was the most efficient. On the other hand, the manner in which the puncture is opened influences the quality of the sieve. The selection of the optimal alternative, the problems appearing during the study and the solutions adopted are described in the paper.

Keywords: Waterjet cut, Abrasive Waterjet AWJ \& Plain waterjet; Polypropylene tableware cut, Cut optimization.

\section{Introdução}

Tecnologia avançada vem sendo empregada para corte de muitos materiais de engenharia, dentre estes os freqüentemente chamados plásticos vêm extensivamente substituindo os metais. Uma tecnologia avançada que pode ser aplicada ao polipropileno é o corte com jato de água pura ou corte com jato de água mais abrasivo.

Recentes investigações tanto teóricas quanto práticas foram realizadas neste campo, no Módulo de Jato Abrasivo do Departamento de Engenharia de Minas e de Petróleo da Escola Politécnica da Universidade de São Paulo ${ }^{[1,2]}$.

Os trabalhos trataram do uso destas técnicas avançadas tendo como material alvo vários tipos de polímeros. Os testes práticos consistiram na confecção de corpos-de-prova em forma de gravata borboleta, permitindo em alguns segundos recortar os mesmos a partir de uma chapa. O corpo-de-prova recortado com faca não fornece tão boa qualidade, além de gerar na peça concentração de tensões. Como conseqüência destas tensões internas no corpo-de-prova, verifica-se no ensaio de tração a ruptura do mesmo nas garras do equipamento, falseando deste modo os resultados dos ensaios.

A tentativa de retirar corpos-de-prova, pelo corte com serra tico-tico, além da geração de calor (soldagem do material plástico) e tensões, o aspecto final da peça apresenta qualidade ainda mais precária ${ }^{[1]}$.

A solução de fabricar um molde para obter peças de formato constante deste corpo-de-prova não atende em geral as exigências, pois o plástico produzido no molde pode ser distinto daquele utilizado nas chapas usuais, além disso,

Autor para correspondência: Wildor T. Hennies, Departamento de Engenharia de Minas e de Petróleo, Escola Politécnica, USP, Av. Prof. Luciano Gualberto 380, CEP: 05508-900, São Paulo, SP. E-mail: wildorth@usp.br 
o molde custa algumas dezenas de milhares de dólares.

Portanto, o método de retirar corpos-de-prova por corte de jato d'água mais abrasivo a partir de chapas previamente selecionadas, é um elemento a considerar para as próprias operações de controle de qualidade dos plásticos ou polímeros. Este corte pode ser feito com jatos d'água de ultra-alta pressão, tanto puros como com abrasivos, e os primeiros estudos realizados foram para retirar os corpos-deprova em chapas da ordem 3 milímetros.

Fabricação de peneiras a partir de chapas com auxílio desta técnica para espessuras maiores de polipropileno, foi um segundo desafio. Como este estudo permitiu adquirir novos conhecimentos sobre o comportamento prático deste material de engenharia, os autores procuram reunir os principais e mais relevantes dados que constituem o objetivo principal deste artigo.

\section{Conceitos Fundamentais}

O corte com jato de água puro e com jato abrasivo é efetuado atualmente por sistemas totalmente automatizados tipo CAD/CAM. O sistema usado é o Modelo 2652A da OMAX, que foi adquirido com o apoio da Fundação de Amparo a Pesquisa do Estado de São Paulo - FAPESP, constituindo o Módulo de Jato Abrasivo da EPUSP ${ }^{[2]}$.

O sistema consta de uma bomba de ultra-alta pressão, uma mesa XY para suporte do material alvo de corte e movimentação do bocal e um sistema de controle constituído de um computador. A bomba de alta pressão do modelo acima é de 30 KW (20HP), e fornece uma pressão da água da ordem de 290 $\mathrm{MPa}$ (42.000 psi). A mesa XY é dotada de um grande tanque de água para coleta dos detritos gerados no corte dos materiais sendo retangular e têm uma área útil de corte de 665,6 $\mathrm{mm}$ (26 polegadas) por $1.331,2 \mathrm{~mm}$ (52 polegadas) donde provem os números do modelo. Existem sobre a mesa, dois cursores orientados por deslocamentos de precisão através de duas guias. $\mathrm{Na}$ extremidade do cursor $\mathrm{X}$ está preso o bocal cujo trajeto pode ser feito para qualquer parte da área de corte. O sistema de controle é realizado através de computador, onde um desenho em CAD (Desenho com Auxílio de Computador arquivo de terminação .dxf) após convenientemente ordenado, é executado por CAM (Manufatura auxiliada por computador) no sistema. Em síntese, o desenho é feito na tela, e o computador o corta através de um "plotter". Como inicialmente referido o corte pode ser feito com jato de água pura, ou com jato de água abrasivo. Existem para isso dois bocais distintos que são o de água pura, e o de água com abrasivos. As figuras $1 \mathrm{a}$ e $1 \mathrm{~b}$ mostram estes esquemas.

No bocal de água pura (Figura 1a), a saída da água ocorre através de um orifício em jóia (rubi ou safira), cujo diâmetro está entre $0,3556 \mathrm{~mm}(0,014$ polegada $)$ e $0,254 \mathrm{~mm}(0,010$ de polegada), a qual está localizada na extremidade do bocal.

No bocal de injeção (Figura 1b) a jóia está alojada mais acima, tendo associado um tubo de mistura ou de foco.

A câmara de mistura é constituída pelo tubo de foco, que possui uma entrada cônica e por um espaço adicional. Através da câmara de mistura é que se dá a entrada do abrasivo.

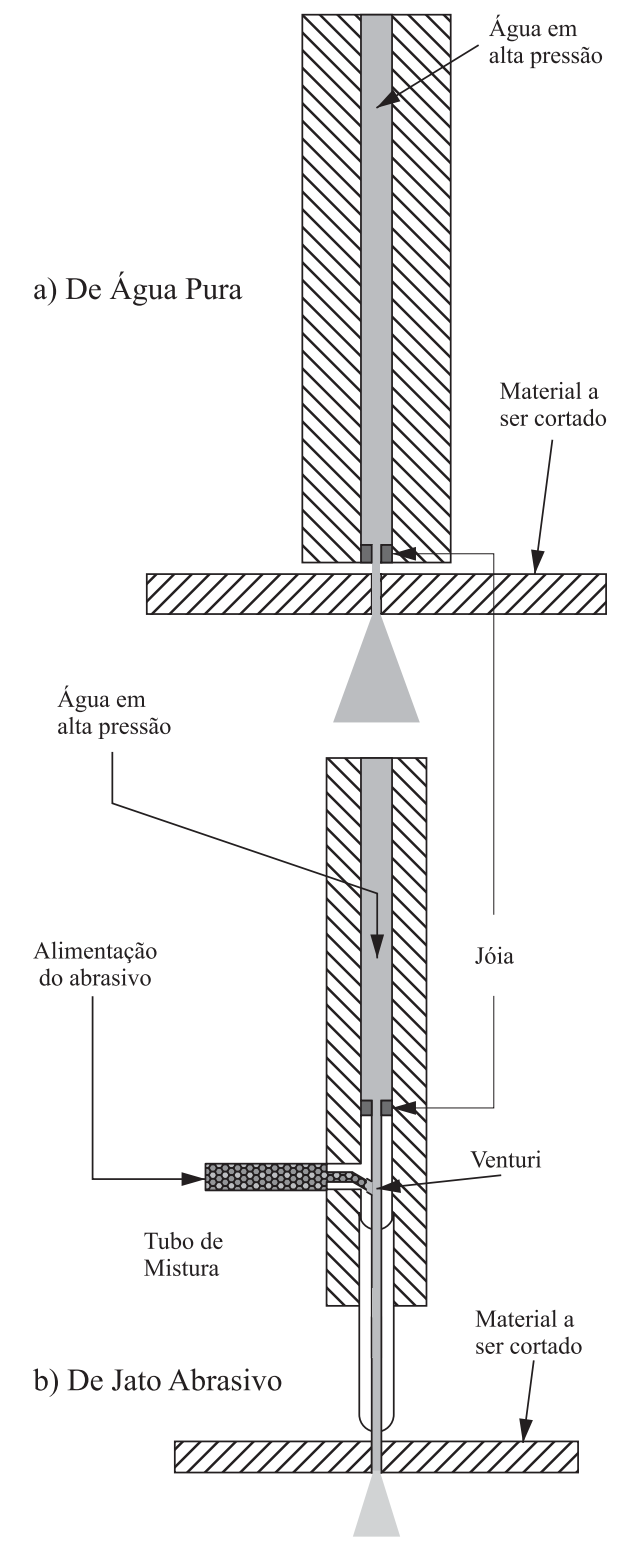

Figura 1. Tipos de bocais de corte

O líquido gerado no orifício da jóia possui uma velocidade de aproximadamente 3 vezes a do som (cerca de $800 \mathrm{~m} / \mathrm{s}$ ) e passa pelo centro do tubo de mistura sugando o abrasivo. Tal mistura é direcionada no tubo antes de atingir o material alvo a ser cortado (vide Figura 1b).

O abrasivo normalmente empregado nestes sistemas é um mineral chamado granada. No presente estudo foi empregada a granada importada da Flow de 80\# cujas características tecnológicas podem ser encontradas em artigo divulgado em 2000 em evento na Grécia ${ }^{[3]}$.

\section{Cortes com jatos de água e abrasivos em materiais plásticos}

O corte num sistema de jato de água abrasivo em geral origina um sulco ou ranhura que possui as características que podem ser observadas na Figura 2. A Figura 2 foi adaptada a partir de desenho de corte em metais.

Examinando-se a seção transversal, na Figura 2, nota-se 


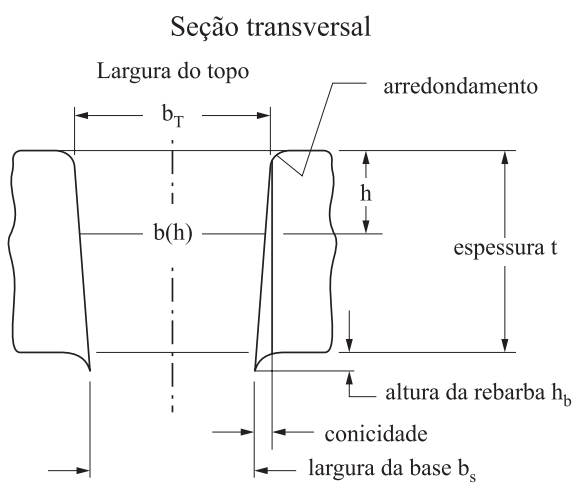

Superfície do corte
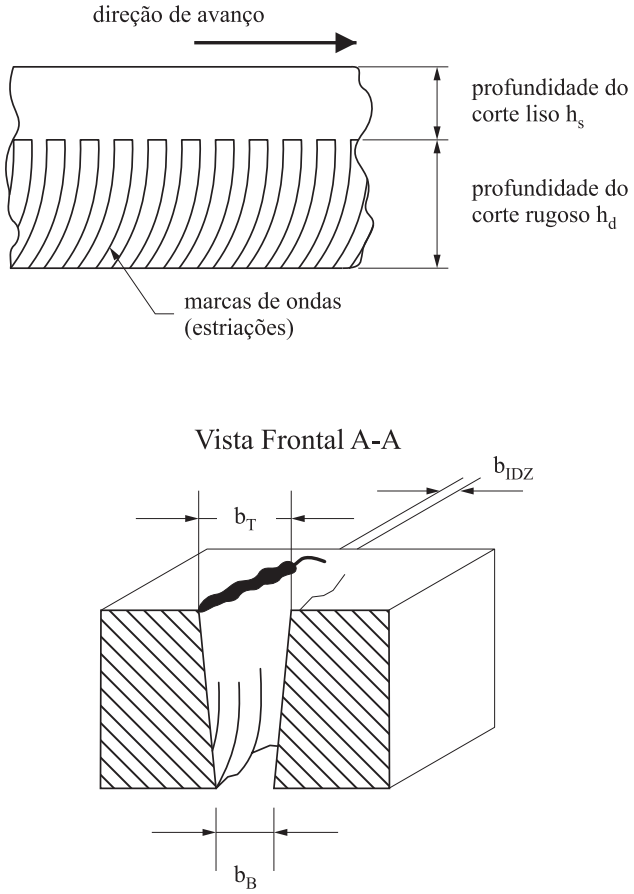

Figura 2. Elementos de sulcos gerados por jatos abrasivos.

que a largura do sulco é, em geral, maior no topo (largura $\mathrm{b}_{\mathrm{T}}$ ) que na base da chapa $\left(b_{s}\right)$. A relação entre estas larguras é normalmente designada de afunilamento. A altura da rebarba, definida como $h_{b}$ no corte de plásticos surge como fiapos de fibras do plástico, possuindo uma altura $\left(\mathrm{h}_{\mathrm{b}}\right)$ mínima.

Examinando a superfície do corte, na Figura 2, duas áreas distintas podem ser observadas: na parte superior onde o mesmo é liso até certa profundidade $\left(\mathrm{h}_{\mathrm{s}}\right)$, e, outra onde corte se torna rugoso ou ondulado $\left(\mathrm{h}_{\mathrm{d}}\right)$. Nesta parte inferior aparecem então, marcas de onda ou estrias.

Finalmente em uma vista frontal tridimensional, observase uma zona de incidência inicial do jato $b_{\text {IDZ }}$, ou seja, uma área onde o abrasivo arredonda o corte devido ao impacto inicial.

Ao se empregar o jato de água pleno ou puro, para o corte, consegue-se superfícies de corte mais retas e lisas em certos tipos de plásticos menos friáveis, enquanto em outros o acabamento da superfície de corte é mais irregular que aquela conseguida com o corte com abrasivo. A experiência prática com o material vai indicar o método mais adequado a ser usado.

\section{Cortes de chapas para fabricação de peneiras de polipropileno}

A obtenção de peneiras de plásticos para certas finalidades específicas é uma necessidade industrial. Para isto, o desenho a ser utilizado deve satisfazer certas necessidades de fluxo de material líquido através das peneiras.

O objetivo do presente trabalho foi de fazer 900 furos de $1,2 \mathrm{~mm}$ de largura com terminações semicirculares, em uma chapa de polipropileno com área de 725 X 143 mm e com uma espessura de $10 \mathrm{~mm}$.

Os estudos iniciaram-se com simulações no equipamento, seguidos de análises de alternativas e de procedimentos para atingir uma boa qualidade de corte dos furos.

\section{Simulações iniciais}

O estudo inicial constituiu-se de, a partir de um desenho fornecido pela empresa, elaborar desenhos em CAD e ordenar os mesmos para permitir a simulação no sistema de corte. A Figura 3 mostra parte do desenho para previsão de tempos de elaboração do corte da área citada.

Foram confeccionados para isto quatro desenhos a saber:

1. TESTEQ5.DXF - Qualidade alta

2. TESTEQ3.DXF - Qualidade média

3. TESTEQ1.DXF - Corte simples

4. TESTEQW.DXF - Corte com água pura.

O tempo de corte de cada modelo foi determinado e os seguintes resultados foram obtidos:

- Na Qualidade alta Q5, com velocidade média do bocal $\left(\mathrm{V}_{\mathrm{m}}\right)$ de $8,962 \mathrm{~mm} / \mathrm{s}$, a abertura de 900 furos demanda 201 minutos.

- Na Qualidade média Q3, com $\mathrm{V}_{\mathrm{m}}$ do bocal de 11,798

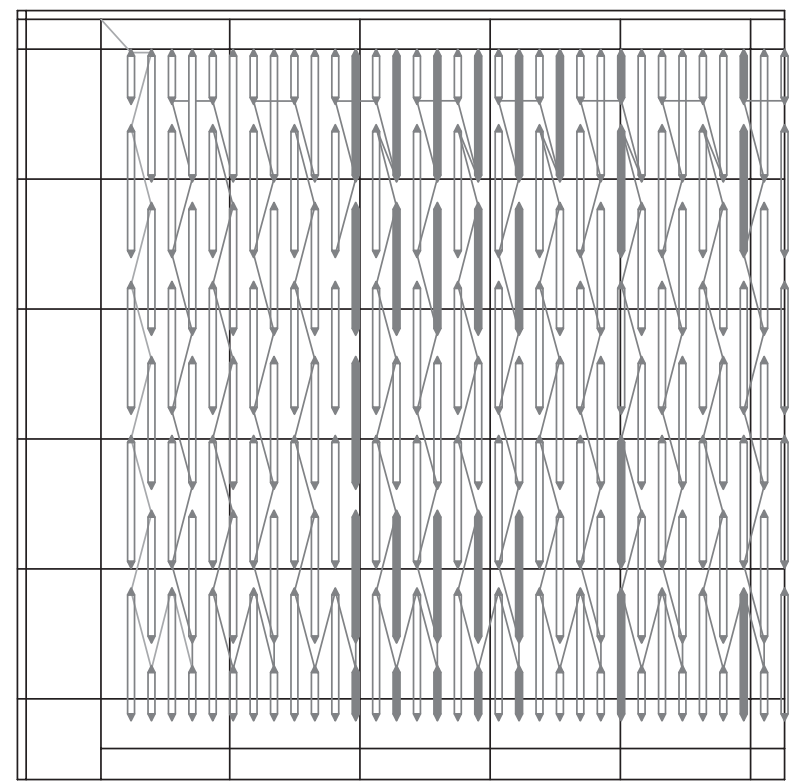

Figura 3. Detalhe de desenho de corte de furos em chapa de polipropileno. 


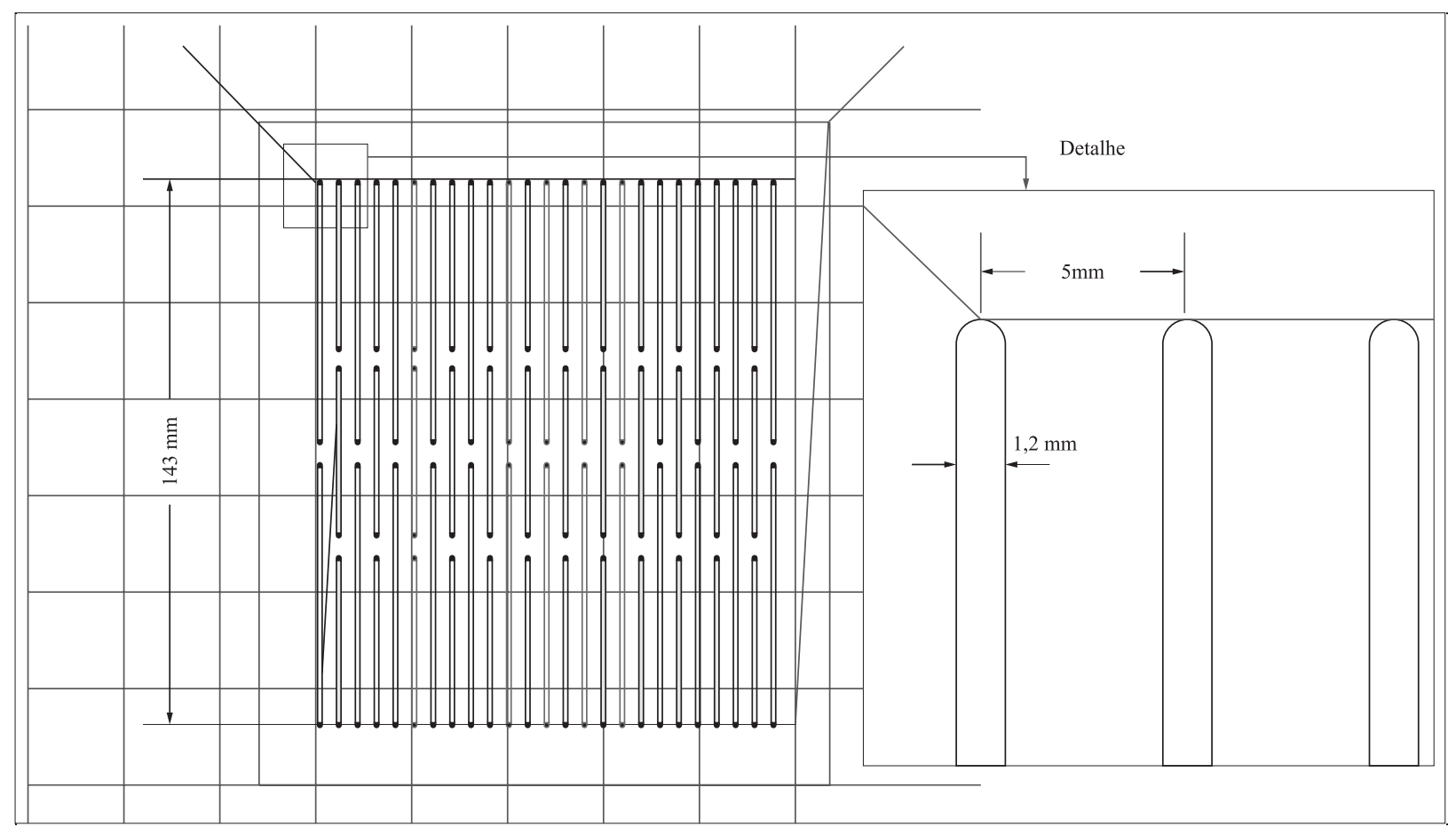

Figura 4. Parte do novo modelo de disposição dos furos com fileiras espaçadas de $5 \mathrm{~mm}$ e com 2 e 3 furos por fila com largura de $1,2 \mathrm{~mm}$.

$\mathrm{mm} / \mathrm{s}$, a abertura dos 900 furos demora 185 minutos.

- No Corte simples Q1, com $V_{\mathrm{m}}$ do bocal de $14,635 \mathrm{~mm} / \mathrm{s}$ a realização dos 900 furos dura 170 minutos.

- No corte com água pura, com velocidade constante de $10 \mathrm{~mm} / \mathrm{s}$, o corte dos 900 furos demora 126 minutos.

Com o objetivo de conservar a relação de vazios por área, procurou-se diminuir o tempo de fabricação a partir da redução do número de furos. A Figura 4 mostra o novo modelo.

Neste desenho, para diminuir o número total de furos, o espaçamento entre as fileiras sucessivas foi aumentado dos 4 $\mathrm{mm}$ iniciais para $5 \mathrm{~mm}$, e ao invés de 10 furos em cada duas fileiras, passou-se a cinco, ou seja, 2 furos na primeira fileira seguidos de 3 na seguinte. Com isso, a área perfurada (altura: $143 \mathrm{~mm}$, comprimento $725 \mathrm{~mm}$ ), que inicialmente previa, 900 furos, resultou em 362 .

\section{Sobre Motivos ou Modelos}

Quanto a modelos vários outros são possíveis. O modelo original dispõe de dois tipos de furos alternados (900 furos) e será chamado de Modelo 55.

O desenho de 362 furos apresentado na Figura 5 será designado de Modelo 23. Modelos ainda mais simples, com um mesmo furo ao longo da chapa darão 145 fileiras de um furo e será chamado de Modelo 11. Finalmente o Modelo 12 , que tem um furo ao longo da peça, alternado com 2 furos na segunda fileira dará cerca de 218 furos. Como estes dois últimos modelos devem ser mais econômicos no corte, a estimativa dos custos dos mesmos deve ser realizada, antes da decisão final.

Na Tabela 1, a avaliação entre a área total da chapa de 1530 por $865 \mathrm{~mm}\left(1.323 .450 \mathrm{~mm}^{2}\right)$ e a área dos furos ou índice de vazamento em porcentagem foi realizada, partindo do modelo padrão do desenho original onde havia 900 furos, e que foi chamado de modelo 55. Neste modelo haviam sido previstos furos com 1,2 mm de largura, com terminações em semi-arco de círculo e espaço entre colunas de furos de $4 \mathrm{~mm}$. A Tabela 1 mostra os resultados dos vários modelos possíveis. Nesta Tabela o modelo de número de furos, espaço entre fileiras de furos, a área dos furos, e sua porcentagem em relação a dimensão da chapa estão indicados nas colunas.

O desenho original, modelo 55, tem maior semelhança com o modelo 11 como pode ser visto tanto pela área de vazamento quanto pela porcentagem de vazios. Contudo os demais, 12 e 23, não apresentam grande desvio em relação ao modelo original 55, quanto à área de vazamento.

Nota-se, que a \% de vazios em relação à área total da chapa, tem números bastante similares.

\section{Ensaios iniciais com jato abrasivo}

Inicialmente, cortes com jatos abrasivos foram realizados em retalhos de polipropileno. O fornecimento de retalhos de polipropileno tornou possível a realização de ensaios utilizando-se

Tabela 1. Cálculo da área de vazamento e sua \% de vazios nos modelos possíveis.

\begin{tabular}{ccccc}
\hline Modelo & $\mathbf{N}^{\circ}$ de Furos & $\begin{array}{c}\text { Filas } \\
\mathbf{m m}\end{array}$ & $\begin{array}{c}\text { Área* } \\
\mathbf{m m}^{\mathbf{2}}\end{array}$ & $\begin{array}{c}\text { Vazio } \\
\mathbf{\%}\end{array}$ \\
\hline 11 & 145 & 5 & 246659 & 18,64 \\
12 & 218 & 5 & 242117 & 18,29 \\
23 & 362 & 5 & 232945 & 17,60 \\
55 & 900 & 4 & 247779 & 18,72 \\
\hline
\end{tabular}

*Área de vazamento 


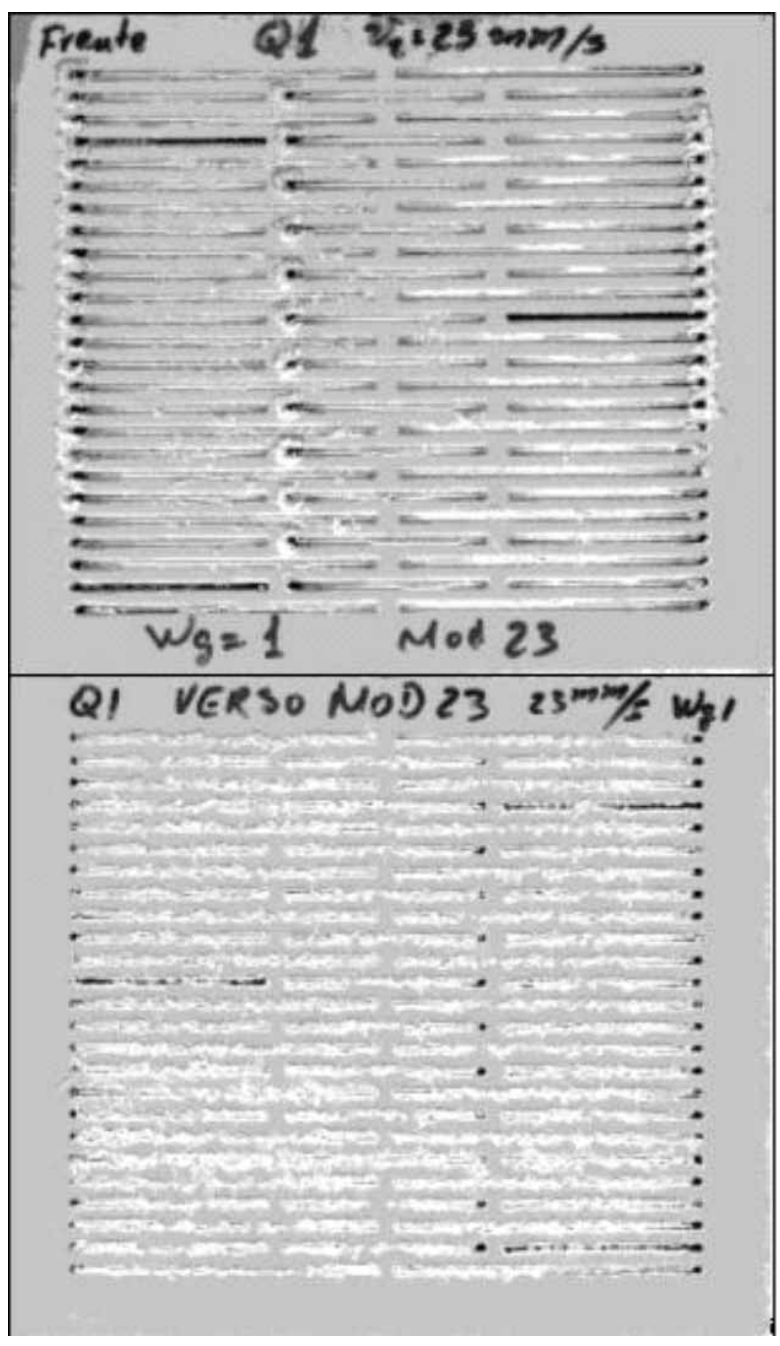

Figura 5. Fotografias do ensaio realizado na qualidade Q1

o modelo 55 para teste e o modelo 23 para os demais ensaios.

Com uso de abrasivos os quatro seguintes ensaios foram feitos resultando em quatro amostras:

Corte simples Q1, tempo de corte: 64 min. Resultado péssimo não recomendado.

Qualidade média Q3, tempo de corte: 73 min. Resultado ruim não recomendado.

Qualidade alta Q5, tempo de corte: 91 min. Resultado regular

Velocidade Constante $Q E$, tempo de corte: $72 \mathrm{~min}$. Resultado a considerar $(\mathrm{v}=25 \mathrm{~mm} / \mathrm{s})$

O corte do polipropileno nacional com abrasivos gera um certo afunilamento no furo aberto, isto é, o furo se estreita na saída do jato. Por isso, em geral os fragmentos de material cortado ficam retidos no interior dos furos abertos.

No primeiro ensaio elaborado da amostra Q1 (não recomendado) o aspecto é péssimo. A velocidade média do bocal utilizada foi de $23 \mathrm{~mm} / \mathrm{s}$. Na Figura 5 pode-se observar, devido ao estreitamento do furo, a retenção do material cortado nas malhas da peneira.

Além disso, pode ser notada na amostra uma certa fusão do material por ter sido utilizado apenas uma oscilação para seu corte o que, possivelmente ocasionou um derretimento ou um aquecimento no início dos cortes.

Tal fato foi corrigido pois nos testes seguintes Q3 e Q5 a fusão do material deixou de existir com o emprego de 3 oscilações no início do corte.

O segundo ensaio Q3, utilizou uma velocidade de translação do bocal de $17 \mathrm{~mm} / \mathrm{s}$. O exame da amostra depois de testada também não recomenda que tal resultado seja utilizado.

Notou-se posteriormente que esta amostra foi extraída de uma chapa de $12 \mathrm{~mm}$ de espessura.

O terceiro ensaio foi realizado utilizando qualidade alta, ou seja, Q5 e a velocidade de translação do bocal de $12 \mathrm{~mm} / \mathrm{s}$.

Também neste caso, a chapa utilizada possuía a espessura de $12 \mathrm{~mm}$, sendo, portanto uma chapa mais grossa. O problema encontrado, neste caso, foi a formação de rebarba como fiapos na saída do jato, quando o corte foi realizado com abrasivo. Utilizou-se então fita adesiva colada na chapa para evitar a rebarba.

As fotografias da Figura 6 mostram a frente e o verso deste

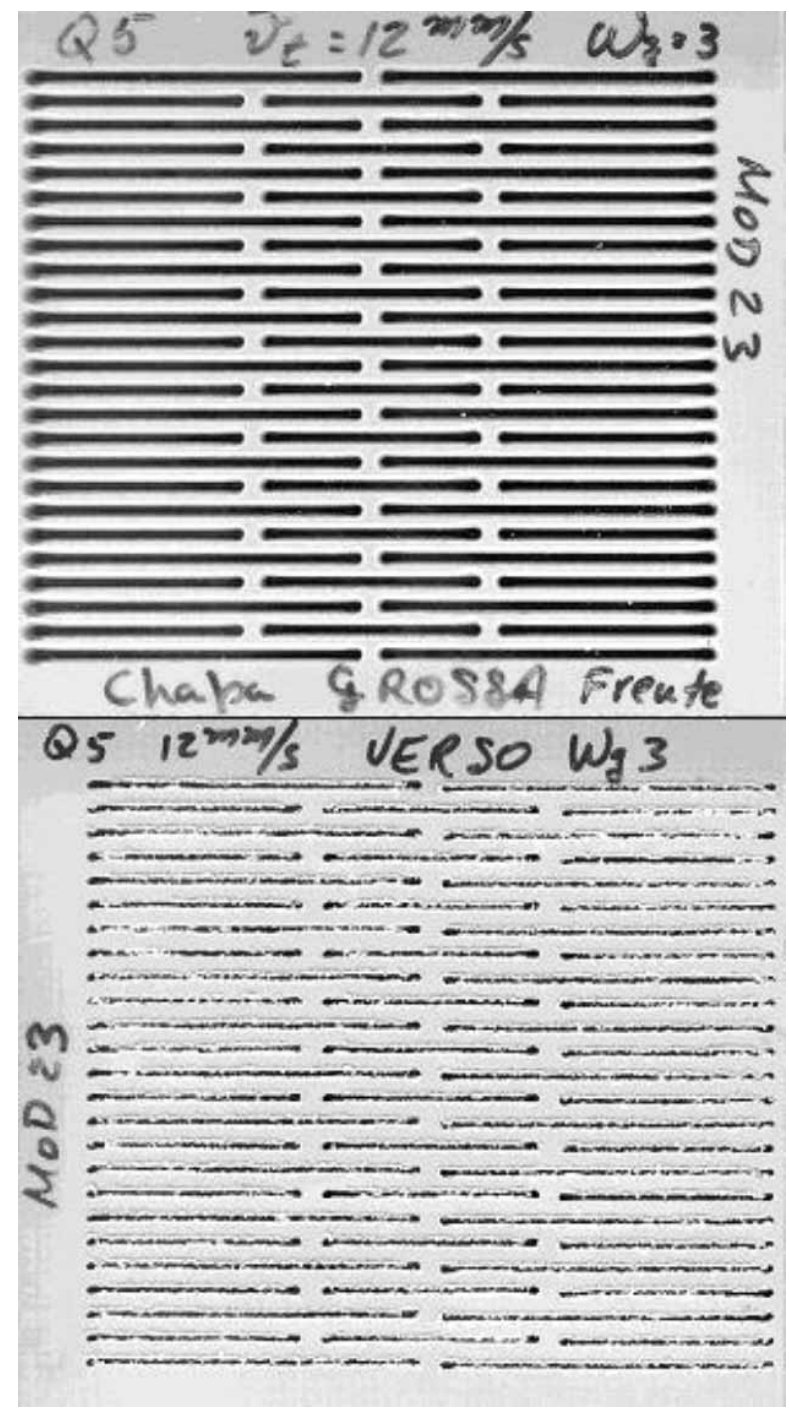

Figura 6 - Fotografias dos ensaios realizados nas qualidades Q5 


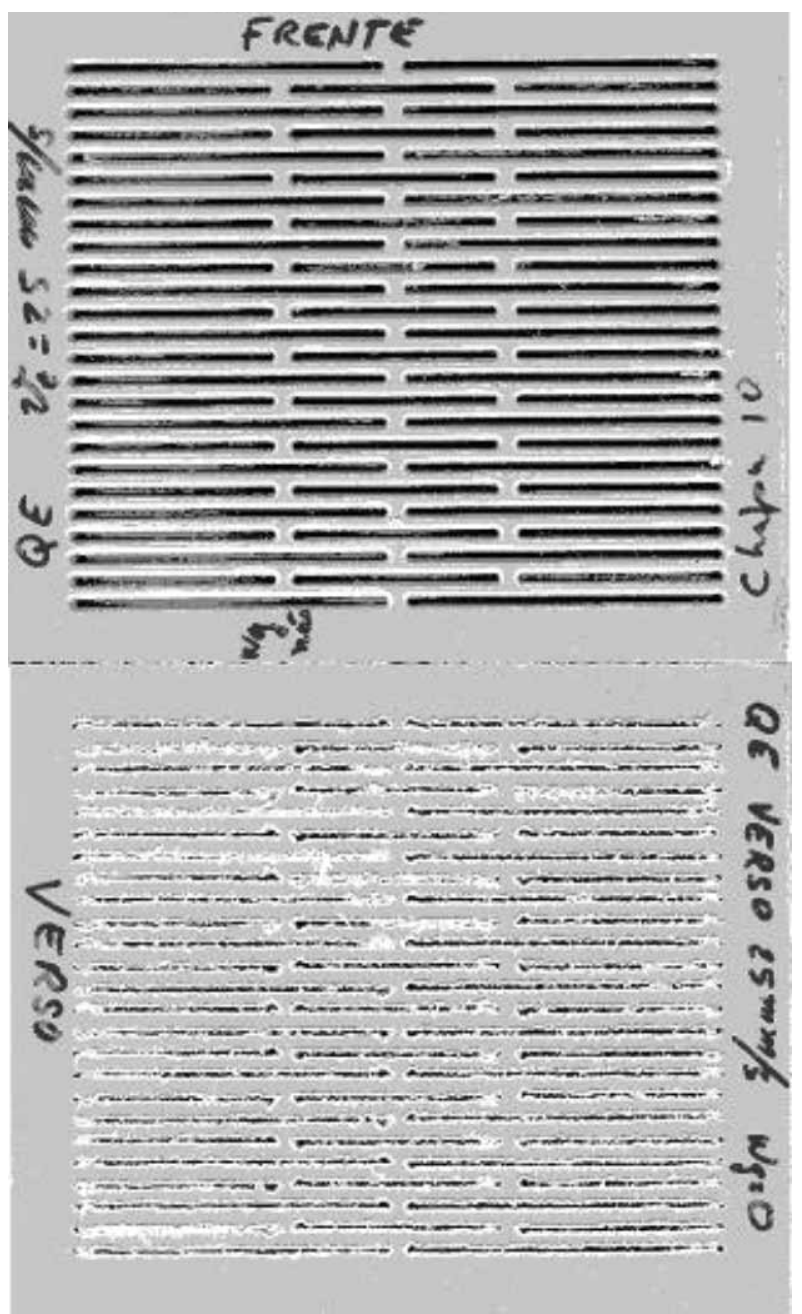

Figura 7. Fotografia da frente e do verso do corte com velocidade constante QE.

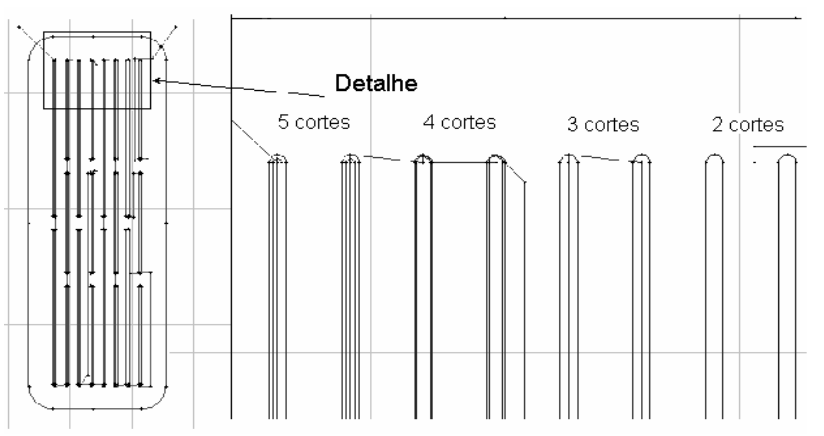

Figura 8. Forma de realizar o corte.

ensaio, onde pode ser notada também a retenção de material cortado nas malhas da peneira. $\mathrm{O}$ resultado foi apenas considerado regular para este quarto teste em qualidade máxima.

Finalmente, um último teste QE foi elaborado usando-se uma velocidade constante (Figura 7) de $25 \mathrm{~mm} / \mathrm{s}$ para o corte, numa chapa padrão de $10 \mathrm{~mm}$, sem oscilação inicial e o resultado mostrou-se bastante satisfatório e bem comparável com o ensaio anterior. Por isso, tal ensaio poderia ser recomendado também.

\section{Ensaios iniciais com jato de água pura}

Além do motivo ou modelo a serem cortados, a forma de efetuar o corte é também um dos problemas. Assim, na tentativa do corte com jato de água puro o modelo 23 também foi usado, e a forma ou o modo diferente de corte foi adotado.

Assim, nestes testes com água pura, tentou-se formas diferentes de abertura com o objetivo de encontrar o melhor modo de fazer a peneira e examinar seus resultados.

Na mesma amostra, as duas primeiras fileiras de furos do Modelo 23 foram realizadas com um corte central, seguido de dois igualmente espaçados de $0,4 \mathrm{~mm}$, estabelecendo 5 linhas de corte para abertura do furo.

Em seguida, o número de linhas foi diminuído para 4 onde as duas bem próximas a periferia distante de $0,1 \mathrm{~mm}$ foram realizadas. Assim 3 linhas de corte foram usadas para abrir as duas fileiras seguintes de furos. Finalmente, apenas o contorno foi cortado, caracterizando as últimas duas fileiras de 2 cortes sendo o corte convencional que foi adotado regularmente.

A Figura 8 mostra o desenho em CAD, do procedimento descrito.

Usando a velocidade constante de corte de $5 \mathrm{~mm} / \mathrm{s}$ a amostra QW, da Figura 9 apresenta os resultados deste teste. Podese perceber que o resultado foi bom, visto que a água pura, diferente do abrasivo, não arredonda a entrada do jato e corta um furo de paredes praticamente paralelas. Contudo, surgiram novamente os inchamentos por alta temperatura na área de início do corte.

Pelo sucesso deste ensaio, o mesmo foi repetido para o corte com velocidade constante de $25 \mathrm{~mm} / \mathrm{s}$. Para a gravação e também aqui, como na água, o corte com 5 passadas parece ser ideal para casos de obtenção de uma abertura limpa e de acabamento relativamente bom, o que pode ser considerado um corte de qualidade aceitável.

\section{Ensaios principais e seleção das alternativas mais econômicas}

Para os ensaios principais foram selecionadas as melhores alternativas, ou, pelo menos, aquelas que durante os estudos preliminares mostraram-se mais adequadas. Para cada

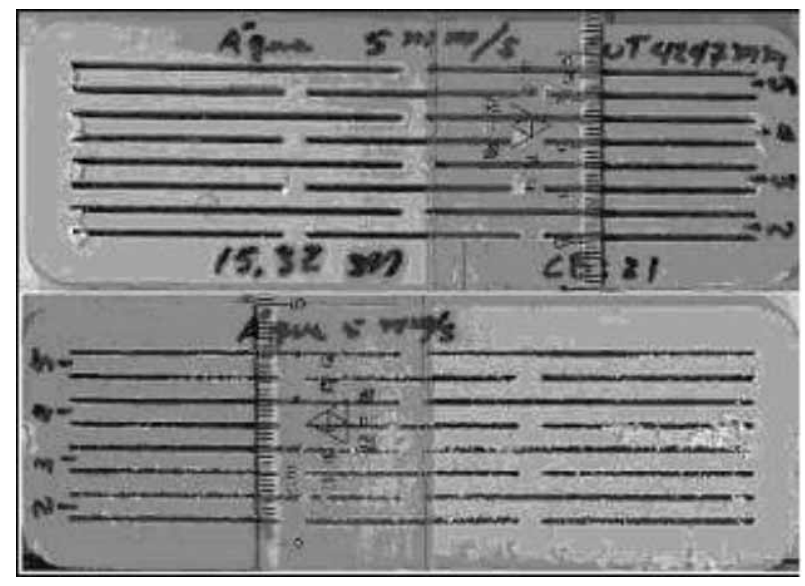

Figura 9. Mostrando QW, corte com água pura. Acima entrada e abaixo saída do jato. 
Tabela 2. Principais resultados da pesquisa

\begin{tabular}{ccccccc}
\hline Modelo & $\begin{array}{c}\mathbf{V} \\
\mathbf{m m} / \mathbf{s}\end{array}$ & $\begin{array}{c}\text { Abras. } \\
(\mathbf{k g})\end{array}$ & $\begin{array}{c}\text { Tempo } \\
(\mathbf{M i n} .)\end{array}$ & Qual. & $\begin{array}{c}\mathbf{N}^{\circ} \text { de } \\
\text { Furos }\end{array}$ & $\begin{array}{c}\text { Água } \\
(\mathbf{L})\end{array}$ \\
\hline 11 & 5 & 0,0 & 350 & Água & 145 & 1077 \\
11 & 25 & 20,9 & 86 & *Etch & 145 & 266 \\
11 & 13 & 47,7 & 170 & Q5 & 145 & 523 \\
12 & 5 & 0,0 & 348 & Água & 218 & 1072 \\
12 & 25 & 20,7 & 95 & Etch & 218 & 292 \\
12 & 12 & 53,4 & 195 & Q5 & 218 & 601 \\
23 & 5 & 0,0 & 345 & Água & 362 & 1063 \\
23 & 25 & 20,2 & 112 & Etch & 362 & 344 \\
23 & 11 & 64,4 & 244 & Q5 & 362 & 752 \\
\hline
\end{tabular}

Nota: *Etch: modo de corte em que a velocidade de translação do bocal é constante.

alternativa foi criado um desenho simulado de forma a estimar o tempo de execução e o custo do trabalho. Apenas os casos que deram bons resultados nos ensaios preliminares foram considerados, ou seja, qualidade de corte constante QE, qualidade alta Q5, e corte com água pura QW. Estes testes foram realizados com a melhor forma do corte, ou seja, de 5 passadas para abertura da fenda ou malha.

Além do modelo 23, os modelos ainda não avaliados do tipo 11 e 12 sendo mais econômicos, por terem menor número de furos, foram também simulados. Na Tabela 2 estão indicados os resultados destas simulações e os tempos de fabricação das áreas unitárias em horas ou minutos de onde resultam seus preços.

$\mathrm{Na}$ Tabela 2, verifica-se que o corte com uso de abrasivo a velocidade constante de $25 \mathrm{~mm} / \mathrm{s}$ apresenta os melhores resultados. Em termos de tempo de confecção, os menores tempos são de 86 minutos para o modelo 11, com 145 furos; 95 minutos para o modelo 12, com 218 furos; e, finalmente de 112 minutos para o modelo 23, com 362 furos.

Para se ter uma idéia de como tais furos ficarão na prática, a mesma velocidade constante de corte de $25 \mathrm{~mm} / \mathrm{s}$ foi usada para fabricar as 3 amostras de 8 fileiras de furos acima estimadas dos modelos 11, 12 e 23. Na Figura 10 está o desenho destas 3 amostras que foram preparadas no sistema de jato abrasivo.

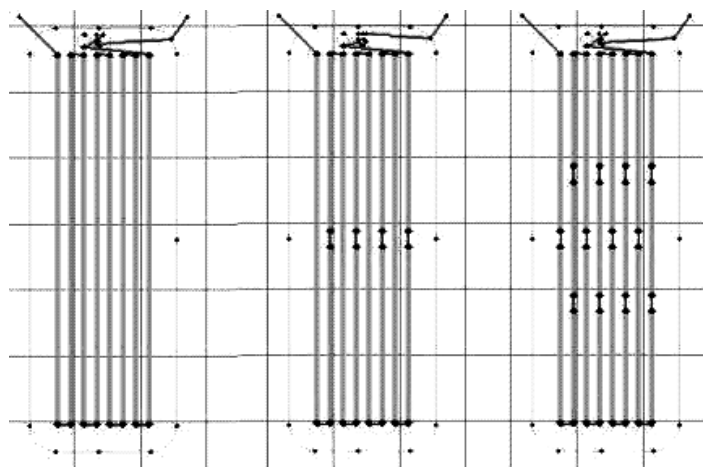

Figura 10. Desenho CAD das amostras dos modelos 11, 12 e 23.
As fotos da Figura 11 mostram alguns detalhes das fotografias das peças das amostras produzidas com os desenhos da Figura 10, onde a velocidade constante QE de $25 \mathrm{~mm} / \mathrm{s}$ foi usada.

Na Figura 11 vê-se a parte da frente, ou seja, o lado no qual incide o jato abrasivo, sendo mais arredondado e largo. Em baixo observa-se para os três modelos, o lado de saída do jato retilíneo e as medidas efetuadas mostram afunilamento da ordem de $20 \%$, ou seja, a largura do corte ao invés de ser de 1,2 $\mathrm{mm}$ na saída é da ordem de 1,0 $\mathrm{mm}$.

\section{Ensaios finais com outras alternativas mais econômicas}

Nos estudos para a seleção do método mais econômico para abrir furos de drenagem em chapas de polipropileno, foram realizados experimentos adicionais, sucedidos de algumas medidas para avaliar o afunilamento com a pretensão de adicionar elementos para uma decisão final.

Os valores ótimos de $25 \mathrm{~mm} / \mathrm{s}$ em velocidade constante mostraram-se os mais razoáveis e seus preços nos três modelos 11,12 e 23 foram os mais atrativos.

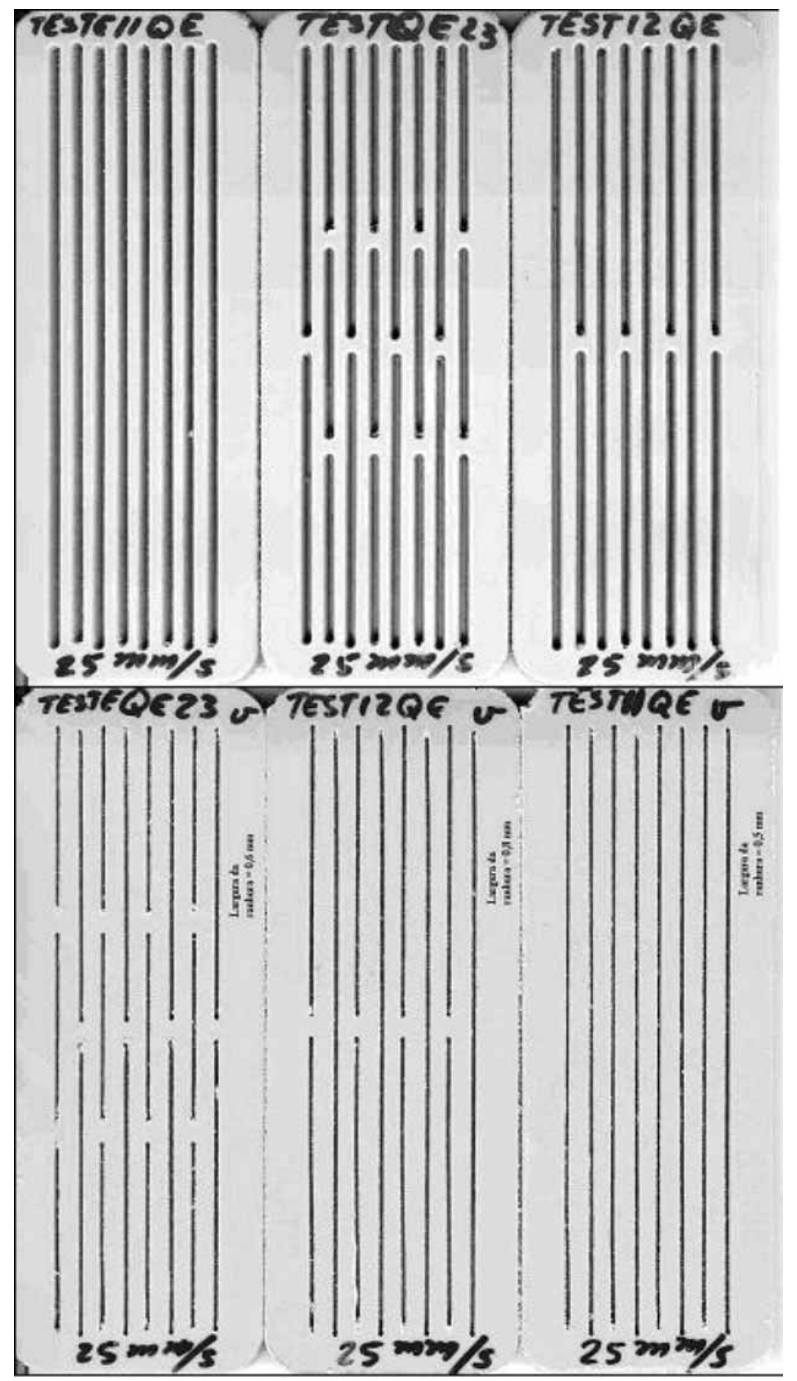

Figura 11. Entrada/saída do jato abrasivo nos modelos 11, 12 e 23, qualidade QE. 
Tabela 3. Resultados de ensaios adicionais com maior velocidade de corte.*

\begin{tabular}{cccccc}
\hline Mod. & $\begin{array}{c}\text { V } \\
(\mathbf{m m} / \mathbf{s})\end{array}$ & $\begin{array}{c}\text { Abras. } \\
(\mathbf{k g})\end{array}$ & $\begin{array}{c}\text { Tempo } \\
(\mathbf{m i n})\end{array}$ & $\mathbf{N}^{\mathbf{0}}$ de Furos & $\begin{array}{c}\text { Água } \\
(\mathbf{L})\end{array}$ \\
\hline 11 & 25 & 20,9 & 86 & 145 & 266 \\
12 & 25 & 20,7 & 95 & 218 & 292 \\
23 & 25 & 20,2 & 112 & 362 & 344 \\
23 & 35 & 14,0 & 91 & 362 & 281 \\
23 & 40 & 13,4 & 89 & 362 & 275 \\
23 & 50 & 11,0 & 82 & 362 & 251 \\
\hline
\end{tabular}

* Utilizou-se qualidade de corte Etch a velocidade constante.

Conforme um consenso geral, o modelo 23, com maior número de furos, é o preferido. Elaborou-se então corposde-prova adicionais deste modelo com velocidades constantes maiores de translação do bocal para a abertura dos furos da peneira.

Assim, 4 novos ensaios foram realizados a velocidade de $35 \mathrm{~mm} / \mathrm{s}, 40 \mathrm{~mm} / \mathrm{s}, 50 \mathrm{~mm} / \mathrm{s}$, e preparadas amostras destes ensaios em oito fileiras, do modelo 23 .

Na Tabela 3, estão os modelos da Tabela 2 (linhas 1 a 3), além dos novos ensaios, que após devidamente simulados no equipamento são relacionados como resultados adicionais (linhas 4 a 6).

Dois elementos são primordiais quando se realizam testes experimentais com jatos abrasivos que são:A largura no topo do corte $\left(B_{T}\right)$ e a largura na face inferior do corte $(B b)$.

A largura no topo do corte é a medida da ranhura do corte no plano superior do corpo-de-prova, ou seja, na superfície que recebeu diretamente o impacto do jato. A largura na face inferior do corte $\left(\mathrm{B}_{\mathrm{b}}\right)$ é, como o nome indica, a largura do corte medida na parte inferior do corpo-de-prova, ou seja, na saída do jato.

No caso dos presentes experimentos, a medição deste valor foi executada através do exame dos corpos-de-prova na frente de entrada do jato abrasivo e no verso, ou seja, na saída do jato abrasivo. Estes dois valores (largura no topo do corte e largura na face inferior do corte) definem o afunilamento do corte $\left(T_{R}\right)$. Seu valor foi obtido através do quociente da largura no topo do corte $\left(B_{T}\right)$ e da largura na face inferior do corte $\left(B_{b}\right)$. Durante todos os experimentos, o valor de $T_{B}$ se

Tabela 4 - Valores em mm avaliados nas amostras cortadas

\begin{tabular}{ccccc}
\hline Modelo & $\begin{array}{c}\mathbf{V} \\
(\mathbf{m m} / \mathbf{s})\end{array}$ & $\begin{array}{c}\text { Frente BT } \\
(\mathbf{m m})\end{array}$ & $\begin{array}{c}\text { Verso Bb } \\
(\mathbf{m m})\end{array}$ & Afunilamento \\
\hline 11 & 25 & 1,2 & 0,50 & 2,40 \\
12 & 25 & 1,2 & 0,80 & 1,50 \\
23 & 25 & 1,2 & 0,65 & 1,85 \\
23 & 35 & 1,2 & 0,50 & 2,40 \\
23 & 40 & 1,2 & 0,70 & 1,71 \\
23 & 50 & 1,2 & 0,80 & 1,50 \\
\hline
\end{tabular}

Afunilamento ou conicidade
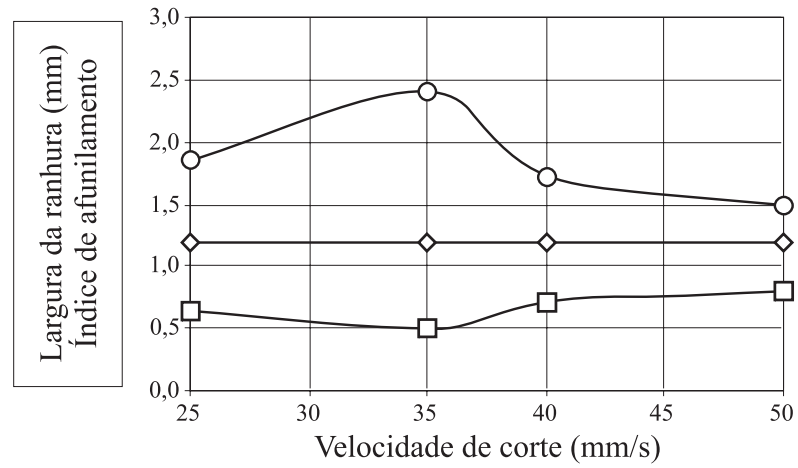

$\prec$ Frente BT $\square-$ Verso BB $-c$ - Afunilamento

Figura 12. Índices de afunilamento no modelo 23

mostrou maior que a unidade, pois os valores de $B_{T}$ sempre foram maiores que os de $B_{b}$. Este tipo de corte apresenta afunilamento convergente. Pode-se dizer que a largura do jato diminui na medida em que atravessa o corpo-de-prova. A Figura 2 ilustra estes dois parâmetros em uma superfície cortada.

Na Tabela 4 estão os valores avaliados em mm de espessura dos sulcos abertos pela máquina nos 3 modelos anteriores (11,12 e23) e aqueles 2 novos (23) ensaios com maiores velocidades de corte.

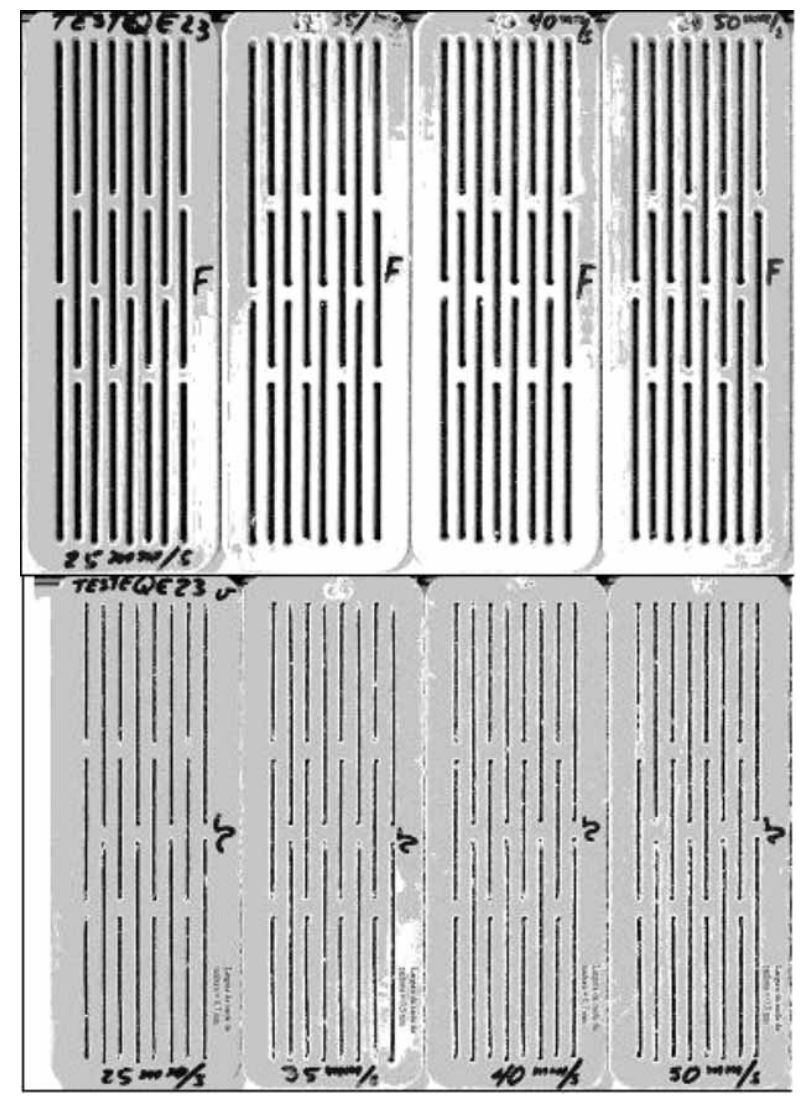

Figura 13. Fotografias das amostras QE frente e verso de 25, 35, 40 e 50 $\mathrm{mm} / \mathrm{s}$. 
A colocação num gráfico dos 5 ensaios do modelo 23 (Figura 12) mostra que o afunilamento apesar de existir não mostra uma tendência clara. Neste gráfico estão também os valores em $\mathrm{mm}$ da largura do corte no topo ou entrada do jato abrasivo e na base, ou saída do mesmo na amostra de 8 fileiras de furos preparadas.

A Figura 13 mostra as fotografias do resultado da amostra QE. Acima a entrada do jato abrasivo com velocidades de corte constantes de 25, 35, 40 e $50 \mathrm{~mm} / \mathrm{s}$. Embaixo, a saída do jato abrasivo com as mesmas velocidades.

Em atenta observação pode-se perceber que a quase inexistente rebarba a $25 \mathrm{~mm} / \mathrm{s}$ na amostra à esquerda, aumenta de modo gradual na outra extremidade direita de $50 \mathrm{~mm} / \mathrm{s}$.

\section{Conclusões}

Como principais conclusões desta pesquisa de otimização de corte de chapas de polipropileno para a fabricação de peneiras, algumas considerações importantes podem ser estabelecidas:

- $\mathrm{O}$ uso dos padrões de qualidade que o sistema fornece por vezes não é aconselhado quando novos serviços são executados.

- Testes em amostras do material são necessários para observação dos resultados.

- No corte de chapas de polipropileno com espessura de $10 \mathrm{~mm}$, os melhores resultados foram obtidos adotando-se uma velocidade de corte $25 \mathrm{~mm} / \mathrm{s}$, quando se emprega jato abrasivo e $5 \mathrm{~mm} / \mathrm{s}$, quando o corte é realizado com jato de água pura.

- A forma de corte ideal da abertura da malha da peneira consiste numa espiral regular, cortando-se inicialmente a parte central do furo e, a seguir, em quatro linhas paralelas espaçadas de $0,4 \mathrm{~mm}$ até atingir a periferia do furo, com 1,2 $\mathrm{mm}$ de largura, com extremidades em semicírculo.
- Com certo sacrifício em qualidade, e por economia, podese dobrar a velocidade de corte, com aparecimento de certo número de rebarbas, ou fiapos de plástico.

- A tentativa de utilizar o afunilamento como auxiliar de seleção foi pouco convincente.

- A diminuição do número de furos conduz a menores tempos de execução do corte e diminuição dos custos.

\section{Referências Bibliográficas}

1. Martín Cortés., G. R., Anadão, P.; Lima, V. A. C.; Wiebeck, H.; Díaz, F. V.; Hennies, W. T.; Lauand, C. T. Corte de corpos-de-prova de materiais poliméricos com jato de água de ultra-alta pressão. In: VIII ${ }^{\circ}$ SIMPÓSIO LATINOAMERICANO DE POLÍMEROS, VI ${ }^{\circ}$ CONGRESSO IBERO-AMERICANO DE POLIMEROS, 2002, Acapulco. Livro de Resumenes. Acapulco, México, p 546-547, (2002).

2. Lauand, C. T.; Martín Cortés, G. R.; Hennies, W. T.; Ciccu, R. 2000 The Brazilian Program of High Pressure Water Jet to Cut Ornamental Rocks. In: International Conference on Environmental Issues and Waste Management in Energy and Mineral Production, 6, Calgary, 2000. Proceedings. Calgary, p. 711-16, (2000).

3. Martín Cortés, G. R.; Lauand, C. T.; Hennies, W. T.; Ciccu, R. 2000 Abrasives in Water Jet Cutting Systems. In: International Symposium on Mine Planning and Equipment Selection, $9^{\text {th }}$ Athens, Greece Rotterdam, Balkema, p.641-645, (2000).

Enviado: 26/11/03

Reenviado: 09/06/04

Aprovado: 19/06/04 